\title{
Student-Industry Project Identification of Favourable Conditions through a Success Story
}

\author{
Jean Brousseau, Professor \\ Simon Bélanger, Research Assistant \\ Abderrazak ElOuafi, Professor
}

\author{
Jean Rioux, Engineering Student \\ Michael Landry, Engineering Student
}

\author{
Université du Québec à Rimouski (UQAR) \\ Département de mathématiques, d'informatique et de génie \\ Frédéric Gauvin, Engineer, Premier Tech Systems \\ Steve Côté, Engineer, Premier Tech Systems
}

\section{Email contact: Jean Brousseau@uqar.qc.ca and Abderrazak ElOuafi@uqar.qc.ca}

\begin{abstract}
Design is one of the key elements of any engineering program. According to the Canadian Engineering Accreditation Board (CEAB), design is a creative, interactive and often open-ended process subject to constraints, which may be governed to varying degrees by standards or legislations depending upon the discipline. Industry-based projects are excellent opportunities to help engineering students develop design skills. The benefits of such projects can be very valuable for both the students and the industry partner. However, they do not always lead to success. Through the presentation and analysis of a studentindustry success story, the favourable conditions of a joint project are presented in this document. As expected, the most significant success conditions are the students' determination and the partner's commitment, both being correlated. In order to work towards a project's success, the university training team has to ensure that the win-win conditions remain present for the duration of the project.
\end{abstract}

\section{Introduction}

Engineering design is a mandatory component of all accredited engineering programs. In fact, the $\mathrm{CEAB}$ [1] has criteria for curriculum content that ensure a foundation in mathematics and basic sciences, a broad preparation in engineering sciences and design, as well as an exposure to non-technical subjects that complement the curriculum. For each content component, the $\mathrm{CEAB}$ has qualitative and quantitative criteria. In relation with design, the $\mathrm{CEAB}$ requires a significant design experience and a minimum of 225 accreditation units out of a total of 1,800 (minimum).
Design is a multifaceted and cross-disciplinary competency [3]. Because it is acquired with experience [4], based on methodologies, techniques and tools [5], it is advisable to provide students with the opportunity to participate in a variety of design activities throughout their curriculum. In that context, project-based design courses provide real-world conditions for the development of design skills.

Project-based design courses are an important part (approximately one-sixth) of UQAR's engineering programs. During their first year, students undertake a design course that includes a project with a non-profit organization [2], in their third and fourth year design courses, students are encouraged to work with industry partners.

Student-Industry projects do not always lead to the same level of success and quality. The key elements of joint projects should be a win-win relationship and partnership between students, faculty and the industry.

There are many factors that influence the results attained by the students. The objective of this paper is to identify the conditions that may increase the potential for success in university-industry undergraduate-level projects. In order to help identify the most decisive factors, the paper presents and analyzes a success story. Through the presentation of the different steps carried out by the students, partner contributions, the costs of the project, and the impacts of the project on the partner and the students are pointed out. The paper also provides a list of necessary and decisive conditions underlying successful student industry projects. Finally, it concludes with some strategic thinking related to how the chances of success can be increased. 


\section{Example of a Successful Joint Project}

A recent joint project between the engineering department at UQAR and its business partner Premier Tech Systems (PTS) stands out due to its positive outcome. It is presented here to illustrate what a successful undergraduate level university-industry collaborative effort may look like.

\subsection{Project Description}

\subsubsection{Industry partner}

PTS is a division of Premier Tech that designs and manufactures packaging, screening and recycling systems, in addition to mixing lines and specialized equipment for the peat moss industry. It is a Canadian company that operates on the world market. Its head office is located in Rivière-du-Loup, Québec, approximately $110 \mathrm{~km}$ from UQAR's Rimouski location.

PTS has been an active partner of UQAR's engineering programs for many years. In October 2006, PTS strengthened its affiliation with UQAR by becoming a major partner of NSERC-UQAR Chair in Design Engineering.

\subsubsection{Project selection process}

PTS uses a structured approach to select the projects that are proposed to UQAR students. First, the department heads are asked to submit technical needs that could be enlisted as student design projects. The submissions are then grouped and evaluated according to the following criteria: dependence to company specific expertise, complexity of integration to other machines (constraints and interfaces), use of resources that do not exist within the company, value for the company, and chances of success. The ratings are compiled and the projects with the best scores have better chances of being proposed.

\subsubsection{Project description}

The aim of the project that is presented here is to develop an autonomous module that can measure the compaction of the bales produced by PTS's compression bagging systems. This arises from the desire to improve consistency while eliminating the need for manual product inspection. Moreover, the technology could open new possibilities for closedloop control that would further improve the overall bagging process.
This project ranks amongst the top quarter of all entries to the selection process described above. It is favoured because of its low dependence to company specific expertise as well as its ease of integration to other machines.

\subsubsection{Student design team}

The project is selected by a team composed of two fourth year students and is considered as part of their final project design courses. It is divided into two stages - one for the 2007 fall semester, the second for the winter of 2008 .

\subsection{Project Workflow - Stage 1}

The first stage focuses mainly on concept selection and development.

\subsubsection{Conceptual design}

The team goes through the process of technology development and brainstorming. Several design concepts are evaluated.

PTS - clear set of needs and specifications. UQAR - periodic support and monitoring.

\subsubsection{Proof of concept}

A basic wooden test structure is built in order to evaluate the design concept retained.

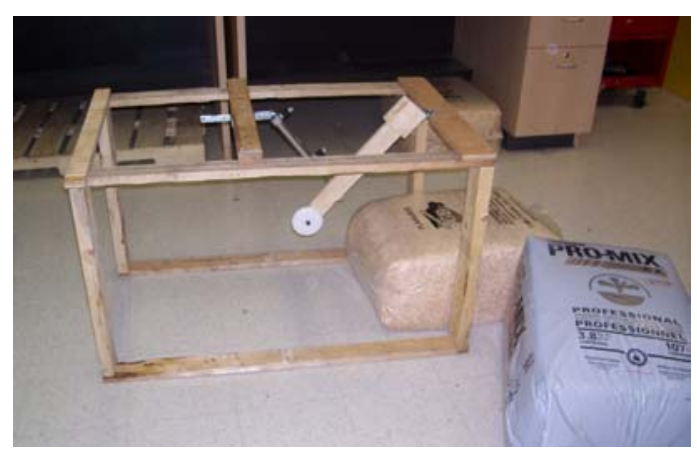

Figure 1. Proof of concept test structure

Simple experiments using various bales and test pressures confirm that the concept is functional and sensitive enough to discriminate between "soft" and "hard" bales.

PTS - key components to build the test structure, meeting with design team. UQAR - technical support, monitoring. 


\subsubsection{Detailed design of stage 1 prototype}

After meeting with PTS engineers, the team sets out to design a working prototype. The goal is to have a test platform that is suitable for production line conditions.

PTS - feedback on proof of concept, specifications of work environment.

UQAR - periodic support and monitoring.

\subsubsection{Stage 1 prototype fabrication}

Fabrication of the first prototype takes place at the university machine shop. The students participate in the work and are assisted by staff technicians for machining and welding operations. Software code for the logic controller is developed and tested.

PTS - components and materials.

UQAR - technical support, fabrication services.

\subsubsection{Stage 1 prototype test and closure}

The prototype is finished in time for the end of the 2007 fall semester.

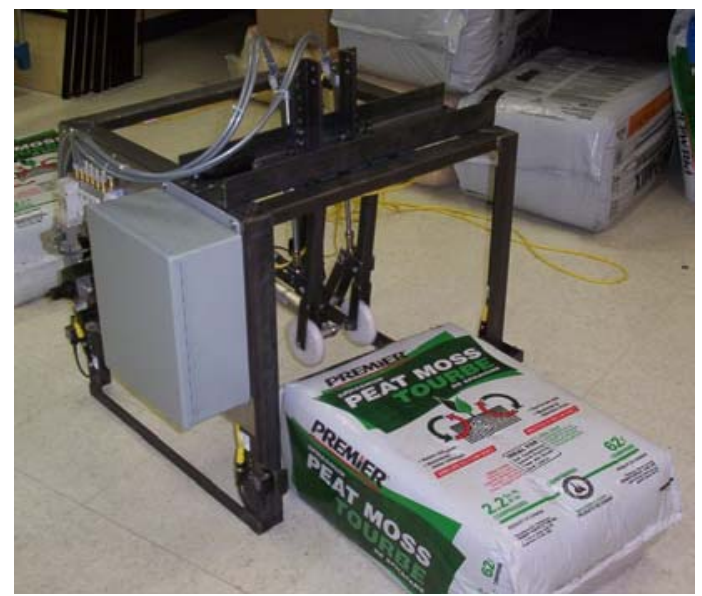

Figure 2. Stage 1 prototype and test bales

A series of tests show that the prototype is fully functional in laboratory settings. The tests also show that the measurements are reproducible.

PTS - meeting with design team, evaluation.

UQAR - technical support, administrative tasks

\subsection{Project Workflow - Stage 2}

The objectives set in the first stage of the project have successfully been met. This second section concentrates on testing, refining, final prototype design, and fabrication. The industry partner imposes specific criteria for design and fabrication.

\subsubsection{Stage 1 prototype test on production line}

The industry partner makes arrangements to hold a test session of the stage 1 prototype on a bagging production line.

PTS - facilities and personnel to install the prototype and run the tests.

UQAR - N/A

\subsubsection{Detailed design of final prototype}

The design of the final prototype draws on the experience gained from the Stage 1 prototype. Also, close collaboration with the industry partner allows key information about specific manufacturing equipment and design criteria to be passed over to the students. For example, the students are asked to adhere to lean design practices and to avoid using materials and fasteners that are not in stock. The result is a design that embodies the company's philosophy and is very likely to become a finished product as such.

The final model and drawings are done with the CAD software used by PTS. The layout format, part numbering and material identification codes follow the company's established standards.

PTS - Feedback from tests, meeting, review of final design, minor modifications to model. UQAR - CAD software license, periodic support and monitoring.

\subsubsection{Final prototype fabrication}

The project is notable for the seamless fabrication and assembly of the final prototype. The parts are manufactured quickly and cost-effectively at the client's facilities using stock materials and standard processes. Final assembly is done by the students and requires only a few hours.

PTS - components, materials, fabrication services, painting, shipping.

UQAR - technical support. 


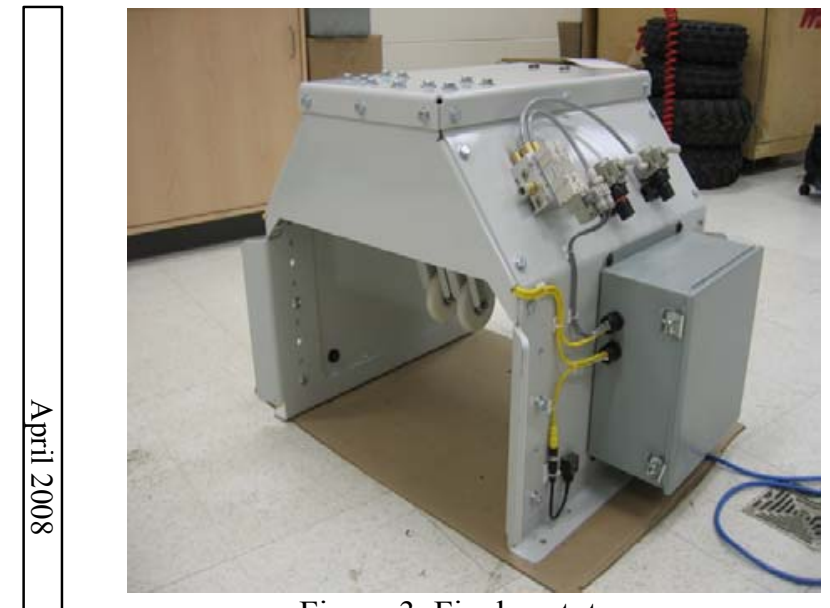

Figure 3. Final prototype

\subsubsection{Project closure}

A public presentation of the project is held at UQAR. The final prototype and associated documents are handed over to PTS.

PTS - presence at final presentation, meeting with design team, administrative tasks.

UQAR - evaluation, administrative tasks.

\section{Inquiry into the Project's Success}

The success of the project can be attributed in great part to the student's good hard work but the surrounding conditions should not be overlooked. Keeping that in mind, a summary of the contributions, benefits and favourable conditions of the project is presented below.

\subsection{Contributions}

The students invested a considerable amount of time and effort. There is no doubt that they spent more than the course's required minimum and they had the attitude and determination to succeed. This was amplified by the fact that the project provided a good source of motivation for them. The match between the team and project surely was adequate and beneficial in that regard.

The university provided a suitable work environment as well as the required support and technical resources. These are varied and range from general and technical guidance to software licenses and fabrication facilities. No costs are associated with these services as they are considered as being a part of the academic process.
The industry partner's contributions are summarized in Table 1 below.

Table 1. Premier Tech Systems contributions

\begin{tabular}{|c|c|}
\hline Description & Cost \\
\hline Supervision (130hr. @ \$60/hr.) & $\$ 7,800$ \\
\hline Components & $\$ 4,400$ \\
\hline Materials and fabrication services & $\$ 600$ \\
\hline Total: & $\$ 12,800$ \\
\hline
\end{tabular}

The costs of components, materials and fabrication services are similar to what is encountered in comparable projects. These costs obviously cannot be avoided if a prototype is to be built. However, the industry partner's involvement and associated costs are considerably higher than average. This does reflect in the number of exchanges between the company and students, as well as in the quality of the information received by the students.

\subsection{Benefits}

The project allowed the students to gain valuable design experience in their field of study. They got a chance to interact with and learn from working engineers. The project settings and constraints were representative of what is encountered in the industry, and included elements such as lean design and other manufacturing guidelines. The team was very pleased to be able to test and refine their original design. The final result gives them a great sense of achievement.

The University has a lot to gain from the success of the project. To begin with, it is a prime opportunity to reinforce its partnership with PTS. Moreover, it constitutes excellent portfolio material that can attract other interesting projects. It can also be used as an example case in design courses, as it incorporates all steps of the design process, not to mention that it sets the desired level in terms of project development and other objectives.

One of the goals behind PTS's involvement in student design projects is to identify and attract potential future employees. In this particular case, both students have been offered a position within the company's engineering department and one of them accepted the offer. Otherwise, the technology developed in this project remains a valuable asset for Premier Tech Systems, especially since it could be commercialized with only minor modifications. 


\subsection{Favourable Conditions}

Several elements contributed to the overall project success. First and foremost, the attitude and determination of the students are essential factors that could not be compensated for by any means. In this case, they were reinforced by a combination of motivation coming from the project itself, favourable work environment and adequate support.

The project selection process used by Premier Tech Systems helped to identify certain elements that are favourable in this type of university-industry collaboration. Namely, the fact that the project possesses low dependence to company specific expertise and is relatively easy to integrate to other machines translated in greater autonomy and fewer distractions for the design team. It also helped limit the load on the industry partner.

Project definition played a key role in setting clear and realistic goals. This had a direct effect on motivation and helped steer the project effectively from the early stages.

Clear communications between the different parties allowed the students to progress more rapidly and to avoid unnecessary ambiguities. As a result, the final product is more mature and better adapted to the needs.

The design team was provided with all the necessary resources and support. Many of these were offered by the university, but Premier Tech Systems played a very important role. The project included some constraints that encouraged the students to progress. For example, testing of the prototype forced the team to structure their work to meet the objective, but rewarded them with a unique opportunity to learn. The same can be said of the constraint to use lean design and other guidelines.

\section{Conclusion}

Design is an integral part of the engineering profession and consequently is a mandatory component of all engineering programs. There is no doubt that engineers need to develop design skills during their engineering degree in order to satisfy the expectations of the profession and employers. Design is a multifaceted competency more easily acquired through experience. Industry-based projects give a real-world context for the development of design skills. In such projects, students tackle real-world problems, are placed in the same context as professional engineers and gain valuable design experience while being in touch with professional design engineers.
Student-industry joint projects do not always lead to the same level of success. It appears that the students' determination and the industry partner's commitment are the two most decisive conditions of a project's success. These two conditions are correlated and influence each other. Students' motivation and determination are human factors that need to be supported and preserved all along the project. In that respect, the partner has an important responsibility and role to play. A well-chosen project proposes a real challenge while allowing the students to progress at a stimulating rate with a minimum of supervision from the partner. That being said, a partner that notes good progress from the student team tends to be more willing to commit resources.

Certainly, the project proposed to students should be valuable for the company and feasible in the context of a project-based course. However, a company should avoid proposing a project that could have detrimental effects if not completed on schedule. Finally, an industry partner that wants to benefit from a project has to be ready to contribute to it by providing continuous supervision and financial support.

It is not easy to gather the win-win conditions for a university-industry joint project. University leadership can make a difference and its role is particularly important at the project definition phase. Industry partners can withdraw tangible benefits from a joint project and contribute significantly to the education of young engineers that may later integrate their company.

\section{References}

[1] CEAB: Canadian Engineering Accreditation Board, Accreditation criteria and procedures, 2007.

[2] Brousseau, Jean, Abderrazak ElOuafi and Suzie Loubert, "Service Learning: A Powerful Approach to the Introduction of Engineering Design for Freshmen, CDEN/C2E2 Conference 2007, July 22-24, University of Manitoba, Winnipeg, Canada.

[3] The NSERC Chairs in Design Engineering and Chairs in Environmental Design Engineering, "Towards a Blueprint for Educating Design Engineers: Design Competency", February 21, 2005.

[4] Koen, Billy V., "Toward a Strategy for Teaching Engineering Design”, Journal of Engineering Education, July 1994.

[5] Dally J.W., Zhang G.M., “A Freshman Engineering Design Course", Journal of Engineering Education, April 1993. 